\title{
PENGEMBANGAN MEDIA PAPAN FLANEL WARNA "PANELWA" UNTUK MENGENALKAN WARNA PADA ANAK USIA 4-5 TAHUN DI TK ABA PRINGGOKUSUMAN
}

\author{
Novi Indriyani, ${ }^{1, a)}$, Dwi Hastuti ${ }^{2}$ \\ ${ }^{1,2)}$ Program Studi Pendidikan Islam Anak Usia Dini \\ Universitas Ahmad Dahlan \\ a)Email: novindriyani200@gmail.com
}

\begin{abstract}
Abstrak
Penelitian ini bertujuan untuk mendeskripsikan langkah-langkah pengembangan produk alat peraga edukatif papan flanel warna "Panelwa" untuk mengenalkan warna pada anak usia 4-5 tahun di TK ABA Pringgokusuman. Penelitian ini menggunakan metode Research \& Development $(R \& D)$ menurut Sugiyono. Kelayakan produk didasarkan pada hasil penilaian ahli materi dan ahli media. Instrumen pengumpulan data menggunakan observasi dengan Kepala Sekolah. Teknik analisis data berupa data kualitatif dan data kuantitatif. Hasil penelitian menunjukan bahwa media Papan Flanel Warna "Panelwa" yang telah dikembangkan melalui serangkaian uji coba serta validasi ahli dinyatakan layak dengan revisi. Hal ini didukung oleh penilaian ahli materi dengan prosentase skor 78,33\% termasuk dalam kategori baik dan layak, penilaian ahli media dengan prosentase skor $87,14 \%$ termasuk kategori baik, layak dan perlu revisi. Berdasarkan hasil penelitian yang telah dilakukan dapat disimpulkan bahwa media papan flanel warna "Panelwa" untuk mengenalkan warna pada anak usia dini usia 4-5 Tahun layak digunakan.
\end{abstract}

Kata Kunci: media pembelajaran, papan flanel, anak usia dini

\begin{abstract}
This study aims to describe the steps for product development of the "Panelwa" colored flannel board educational teaching aid product to introduce color to children aged 4-5 years at ABA Pringgokusuman Kindergarten. This study uses the Research \& Development $(R \& D)$ method according to Sugiyono. The feasibility of the product is based on the results of the assessment of material experts and media experts. The instrument of data collection used observation with the principal. Data analysis techniques in the form of qualitative data and quantitative data. The results showed that the "Panelwa" Colored Flannel Board media that had been developed through a series of trials and expert validation was declared eligible for revision. This is supported by the assessment of material experts with a score percentage of $78.33 \%$ included in the good and decent category, the assessment of media experts with a percentage score of $87.14 \%$ including the good, decent and needing revision category. Based on the results of the research that has been done, it can be concluded that the "Panelwa" color flannel board media to introduce color to early childhood aged 4-5 years is feasible to use.
\end{abstract}

Keywords: learning media, flannel board, early childhood

\section{PENDAHULUAN}

Pengenalan warna sangat penting untuk anak usia dini yaitu membantu anak dalam memahami konsep dasar warna dan bentuk untuk kehidupan di masa datang. Proses pembelajaran dan pendidikan pada anak usia dini hendaknya dilakukan dengan tujuan memberikan konsep-konsep dasar yang memiliki kebermaknaan melalui pengalaman yang nyata sehingga anak memperoleh pengetahuan baru. Pengembangan kemampuan kognitif menurut Peraturan Menteri Pendidikan dan Kebudayaan Nomor 146 Tahun 2014 tentang Kurikulum 2013 Pendidikan Anak Usia Dini Pasal 6 Ayat 1 yaitu pencapaian perkembangan anak berdasarkan atas usia. Ruang lingkup kemampuan kognitif terdiri atas pengetahuan umum dan sains, konsep bentuk, warna, ukuran dan pola, konsep bilangan, lambang bilangan dan huruf. 
Kemampuan kognitif anak usia 4-5 tahun salah satunya adalah mengenal konsep warna. Standar tingkat capaian perkembangan pengenalan warna pada anak usia 4-5 tahun yaitu mengenal warna pada benda, mengklasifikasikan benda ke dalam kelompok warna yang sama, warna sejenis maupun kelompok yang berpasangan dengan 2 variasi, mengenal pola warna $\mathrm{AB}-\mathrm{AB}$ dan $\mathrm{ABC}-\mathrm{ABC}$ serta mengurutkan benda berdasarkan 5 seriasi warna (Latif, 2016). Warna merupakan suatu hal yang dilihat seseorang dalam menentukan respon sehingga memberikan kesan dan identitas tertentu (Nugroho, 2008). Pengenalan warna bermanfaat untuk meningkatkan daya pikir serta kreativitas anak, selain itu melalui penglihatan dalam bentuk (warna) anak dapat merasakan dan mengungkapkan rasa keindahan dari adanya warna tersebut (Sutejah, 2016).

Media adalah segala sesuatu yang dapat digunakan untuk menyalurkan pesan dari pengirim pesan kepada penerima pesan sehingga dapat merangsang pikiran, perasaan, perhatian dan minat serta perhatian anak usia dini sedemikian rupa sehingga proses belajar terjadi (Khadijah, 2016). Tujuan penggunaan media pembelajaran adalah membantu guru dalam menyampaikan pesan-pesan atau materi pelajaran kepada siswanya, agar pesan lebih mudah dimengerti, lebih menarik, dan lebih menyenangkan kepada siswa (Sanaky, 2011). Media pembelajaran yang dapat digunakan oleh guru untuk membantu anak dalam mengenalkan warna dapat berupa media pembelajaran salah satunya adalah Papan Flanel Warna "Panelwa".

Media papan flanel Warna merupakan salah satu media pembelajaran yang berperan dalam proses pembelajaran. Media papan flanel warna menyajikan pesan-pesan tertentu kepada anak usia dini. Papan flanel ini dapat dipasang dan dilepas dengan mudah sehingga mempermudah dalam penyimpanannya dan dapat digunakan berkali-kali. Selain digunakan sebagai papan warna, papan flanel ini dapat digunakan untuk menempelkan huruf dan angka-angka (Sukiman, 2016).

Berdasarkan kutipan di atas, dapat dilihat bahwa, pengunaan papan flanel untuk mengenalkan warna pada anak usia dini sudah menjadi suatu kegiatan pendidikan yang menyenangkan bagi anak, maka dari itu peneliti tertarik dan bermaksud untuk mengembangkan media pembelajaran papan flanel warna yang akan digunakan oleh anak usia 4-5 tahun untuk mengenalkan warna pada anak, menunjukkan warna, mengklasifikasikan warna dan mengurutkan benda dari besar ke kecil menurut warna. Selain itu, peneliti juga berharap aspek-aspek perkembangan anak yang lainnya seperti kognitif, sosial emosional, bahasa, fisik motorik, nilai agama dan moral anak dapat berkembang melalui media pembelajaran ini.

\section{METODE PENELITIAN}

Jenis penelitian ini adalah Research and Development $(R \& D)$ atau penelitian dan pengembangan dengan mengacu pada model pengembangan menurut Sugiyono. Prosedur pengembangan media papan flanel warna "Panelwa". Langkahlangkah yang harus diikuti untuk menghasilkan produk meliputi tahap potensi dan masalah, pengumpulan data, desain produk, validasi desain, revisi desain produk, uji coba produk, revisi produk, uji coba pemakaian, revisi produk, dan produksi massal (Sugiyono, 2012). Namun dengan adanya Pandemi Covid 19, Peneliti melakukan mulai dari tahap potensi dan masalah, pengumpulan data, desain produk, validasi desain dan revisi desain produk. Hasil Penelitian pengembangan media "Panelwa" melalui hasil pengolahan data kualitatif dan data kuantitatif yang diperoleh dari validasi ahli media dan validasi ahli materi.

Tahap pengumpulan data ini, peneliti menganalisa kebutuhan yang diperlukan 
yaitu pengumpulan informasi tentang datadata yang ditemukan di lapangan melalui observasi maupun wawancara yang telah dilakukan peneliti di TK ABA Pringgokusuman. Teknik pengumpulan data yang digunakan oleh peneliti adalah data kualitatif dan data kuantitatif. Teknik analisis data dilakukan dengan menggunakan análisis data kuantitatif deskriptif. Data yang dianalisis meliputi análisis kelayakan terhadap alat permainan edukatif yang dikembangkan. Analisis data ini menggunakan Skala Likert yaitu dengan penggunaan 5 kategori yang terdiri dari sangat kurang, kurang, cukup, baik, dan sangat baik. Setiap pernyataan diberi bobot sangat kurang (1), kurang (2), cukup (3), baik (2), dan sangat baik (5).

\section{HASIL DAN PEMBAHASAN}

Produk yang dikembangkan dalam penelitian ini adalah media pembelajaran papan flanel warna "Panelwa". Kegiatan pembelajaran "Panelwa" untuk mengenal warna berupa anak menyebutkan warna, menunjuk warna, mengklasifikasikan warna dan mengurutkan warna dengan pola A, B maupun A, B, C untuk anak usia 4-5 tahun di TK ABA Pringgokusuman.

Uji kelayakan produk dalam penelitian pengembangan ini dilakukan melalui validasi ahli materi dan validasi ahli media. Berdasarkan penilaian yang telah dilakukan pada tanggal 29 Januari 2021 oleh ahli materi Ibu Intan Puspitasari, S.Psi., M.A. Kegiatan evaluasi dilakukan untuk membantu peneliti dalam mendapatkan informasi yang akan digunakan dalam meningkatkan kualitas materi/ instrumen dari media pembelajaran yang dibuat. Saran dari ahli materi adalah sebagai berikut yaitu benda yang dikenalkan untuk anak adalah benda yang terdekat dengan anak, hal ini peneliti mengambil buah dan geometri. Namun geometri belum perlu diperkenalkan ke anak karena warnanya belum spesifik. Dalam hal ini yang diperkenalkan ke anak yaitu benda berbentuk buah dengan warna spesifik yang mendekati warna asli dari buah tersebut.

Penilaian dari ahli media telah dilakukan pada tanggal 15 Februari 2021 oleh Ibu Dwi Hastuti, M.Pd.I. Media pembelajaran pengembangan papan flanel warna "Panelwa" yang telah dilakukan peneliti untuk membantu penelitian dalam meningkatkan kualitas media dari media pembelajaran yang telah dibuat. Penilaian dari ahli media menyatakan bahwa aspek dan indicator instumen disesuaikan dengan kajian pustaka di Bab II, media sangat baik dan layak digunakan dengan revisi. Proses validasi ahli materi dan ahli media menunjukan bahwa media "Panelwa" layak dan baik digunakan sebagai media pembelajaran untuk mengenalkan warna pada anak usia 4-5 tahun di TK ABA Pringgokusuman.

Berdasarkan masukan dari para ahli, peneliti melakukan perbaikan atau revisi produk Media Papan Flanel Warna "Panelwa" yang telah dikembangkan, perubahannya terdapat pada Lingkaran papan "Panelwa" dan benda berbentuk buah yang dibuat sesuai dengan warna buah. Buah yang dibuat awalnya dengan menggunakan kain flanel yang dilem pada bagian tengah, setelah direvisi buah ini diisi dengan dakron dan pinggirannya dijahit dengan tusuk flanel. Perubahannya atau hasil perbaikan dari sebelum dan sesudah revisi dapat diamati pada sajian berikut: 


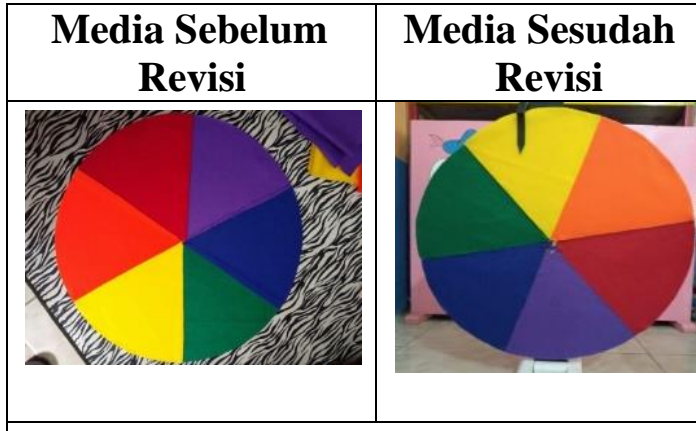

Sebelumnya:

Pembagian Warna tidak simetris, Terlihat kainnya Tumpang tindih

Sesudah Revisi:

Pembagian warna terlihat simetris dengan menggunakan warna primer dan sekunder pada papan flanel warna

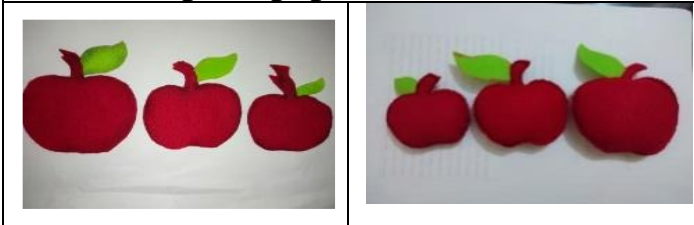

Sebelumnya:

Bentuk buah apel dibuat dengan menggunakan kain flanel berwarna merah dengan cara dua kain di tempel dengan lem, tanpa isian dan tidak dijahit Sesudah revisi:

Pada buah apel dibuat sesuai warna dan bentuk buah aslinya yaitu warna merah dan didalamnya diisi dakron dan pinggirannya dijahit dengan tusuk flanel

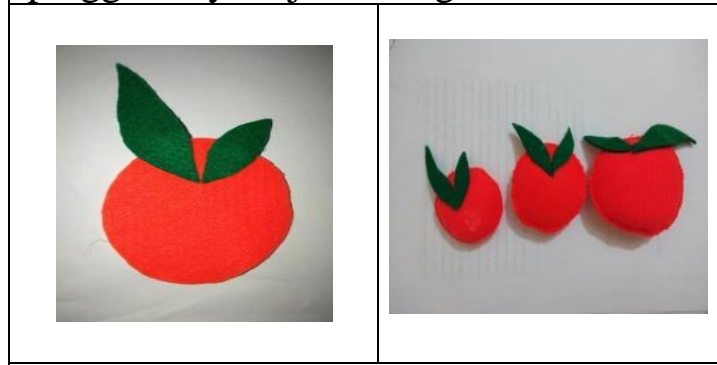

Sebelumnya:

Bentuk buah jeruk dibuat dengan menggunakan kain flanel berwarna jingga dengan cara dua kain ditempel dengan lem, tanpa isian dan tidak dijahit

Sesudah Revisi:

Buah jeruk berwarna jingga termasuk warna sekunder, dibuat sesuai dengan bentuk dan warna buah aslinya didalamnya diisi dakron

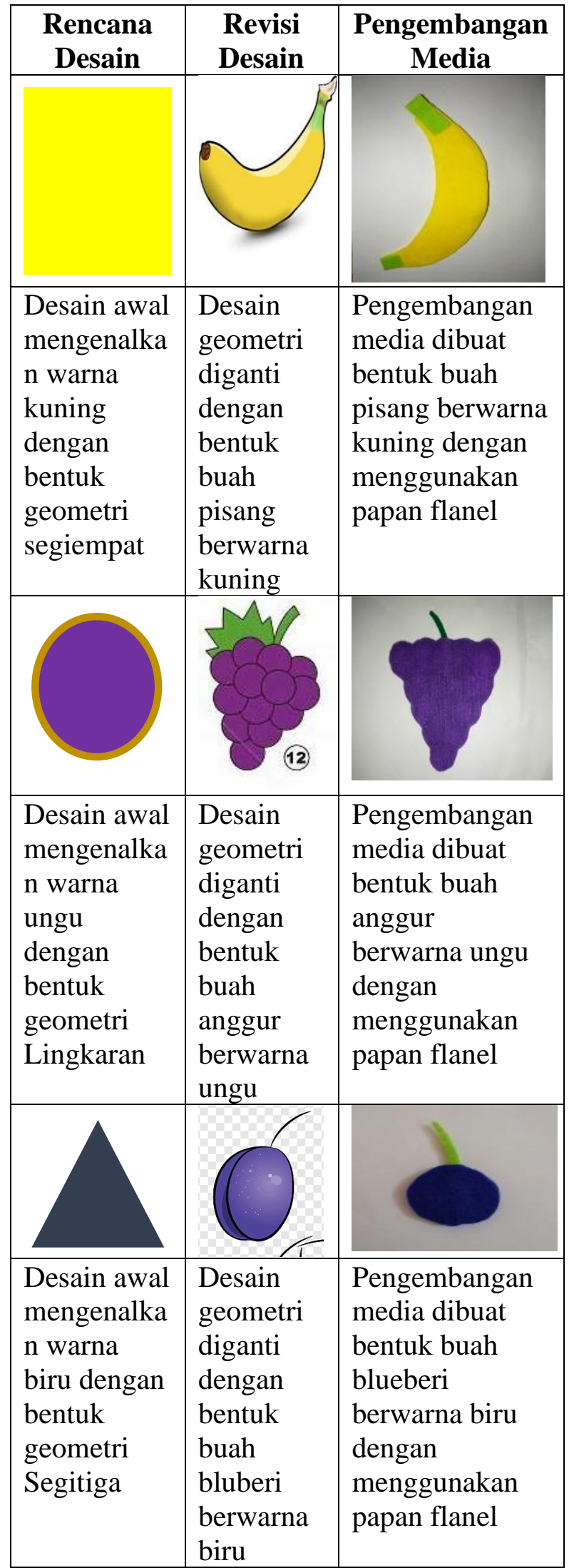




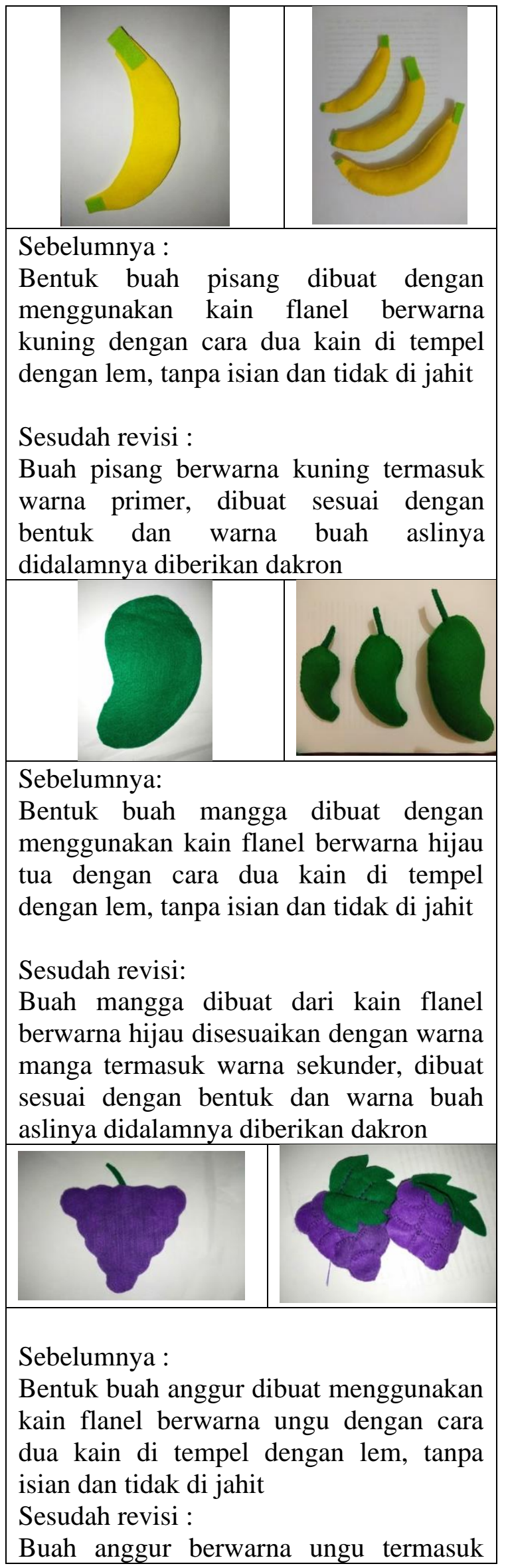

warna sekunder, dibuat dengan caara menyusun kain flanel berbentuk lingkaran dan disatukan dengan cara di jahit sesuai dengan bentuk dan warna buah aslinya dan didalamnya diberikan dakron

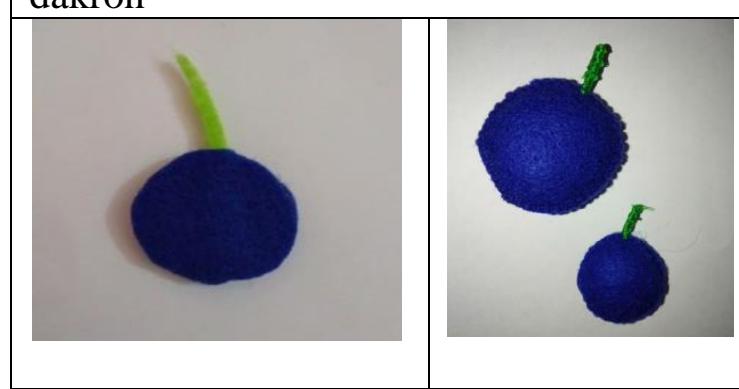

Sebelumnya:

Bentuk buah bluberi dibuat menggunakan kain flanel berwarna biru dengan cara dua kain di tempel dengan lem, tanpa isian dan tidak di jahit

Sesudah revisi:

Buah blueberi berwarna biru, dibuat dengan cara menyusun kain flanel berbentuk lingkaran dan disatukan dengan cara di jahit sesuai dengan bentuk dan warna buah aslinya dan didalamnya diberikan dakron

Media yang digunakan di TK ABA Pringgokusuman masih terbatas. Media APE yang tersedia di TK ABA Pringgokusuman diperoleh dari dana operasional Dinas Pendidikan dan media ini buatan pabrik. Apabila guru membutuhkan media untuk menunjang pembelajaran yang dirasa kurang efektif untuk anak didik, biasanya guru membuat media sendiri dari bahan-bahan sederhana misalnya kertas bekas, kardus bekas sederhana yang di cat agar menarik. Media yang diciptakan guru dirasa kurang menarik untuk anak didik, serta media tersebut tidak bisa bertahan lebih lama.

Oleh karena itu, untuk menyelesaikan masalah belajar mengenal warna pada anak usia 4-5 tahun, dengan mengembangkan media papan flanel warna "Panelwa" yang sesuai dengan karakteristik anak didik. Peneliti tertarik

JECIE (Journal of Early Childhood and Inclusive Education), Vol. 5, No. 1, Desember 2021 
mengembangkan media yang multifungsi dan dapat tahan lama, sehingga peneliti meneliti dengan judul penelitian "Pengembangan Media Papan Flanel Warna "Panelwa" Untuk Mengenalkan Warna Pada Anak Usia 4-5 Tahun di TK ABA Pringgokusuman. Pemilihan alat atau perlengkapan belajar dan bermain, orang tua atau guru sebaiknya memperhatikan ciri-ciri peralatan yang baik seperti (1) desain yang mudah dan sederhana; (2) multifungsi atau serbaguna; (3) menarik; (4) berukuran besar dan mudah digunakan; (5) awet atau tahan lama; (6) Sesuai kebutuhan; (7) Tidak membahayakan anak (Ismail, 2009).

Kelayakan pengembangan media pembelajaran pengenalan warna "Panelwa" adalah sebagai berikut: (a) Penilaian kelayakan ahli media terdapat pada rata-rata $87,14 \%$ pada kategori sangat baik dan layak, (b) Penilaian kelayakan ahli materi pada rata-rata $78,33 \%$ kategori baik dan layak digunakan. Dengan demikian pengembangan media pembelajaran pengenalan warna "Panelwa" untuk anak usia 4-5 tahun atau kelas TK A ini layak digunakan sebagai media dalam proses pembelajaran pengenalan warna.

Berdasarkan masukan dari para ahli, peneliti melakukan perbaikan atau revisi produk Media Papan Flanel Warna "Panelwa" yang telah dikembangkan, perubahannya terdapat pada Lingkaran papan "Panelwa" dan benda berbentuk buah yang dibuat sesuai dengan warna buah. Buah yang dibuat awalnya dengan menggunakan kain flanel yang dilem pada bagian tengah, setelah direvisi buah ini diisi dengan dakron dan pinggirannya dijahit dengan tusuk flanel. Perubahannya atau hasil perbaikan dari sebelum dan sesudah revisi dapat diamati pada sajian berikut:

\section{KESIMPULAN}

Berdasarkan dari hasil penelitian dan pembahasan yang dilakukan oleh peneliti di TK ABA Pringgokusuman dalam pengenalan warna belum dilakukan secara optimal. Adapun yang dilakukan peneliti dalam mengembangkan media apapan flanel warna "Panelwa" untuk mengenalkan warna melalui validasi ahli materi dan ahli media. Tujuan dari pengenalan warna untuk anak usia 4-5 tahun yaitu anak dapat mengenal warna primer dan sekunder, menunjuk warna primer dan sekunder, mengklasifikasikan warna primer dan sekunder dan mengurutkan warna primer dan sekunder.

\section{UCAPAN TERIMA KASIH}

Terima kasih kami ucapkan kepada rekan sejawat, para dosen, dan kepada pihak-pihak yang telah membantu dalam proses penelitian ini sehingga dapat selesai dengan baik dan tepat waktu.

\section{DAFTAR PUSTAKA}

Latif, Mukhtar. (2016). Orientasi Baru Pendidikan Anak Usia Dini. Jakarta : Prenadamedia Group

Nugroho, Eko. (2008). Pengenalan Teori Warna. Yogyakarta: Andi Offset.

Sutejah, E., M, S, Y. (2016). Pengenalan Warna Melalui Penggunaan Model Experiential Learning Pada Anak Usia Dini. Antologi UPI. 1-10. diakses pada 2 Februari 2020

Khadijah. (2016). Pengembangan Anak Usia Dini. Medan: Perdana Publishing

Sanaky, Hujair AH. (2011). Media Pembelajaran. Yogyakarta : Kaukaba.

Sugiyono. (2012). Metode Penelitian Kuantitatif, Kualitatif dan $R \& B$. Bandung : Alfabeta 